\title{
Hygrothermal Studies on GFRP Composites: A Review
}

\author{
Manjunath Shettar ${ }^{1}$, Aakarshit Chaudhary ${ }^{1 *}$, Zaid Hussain ${ }^{1}$, U. Achutha Kini ${ }^{1}$ and \\ Sathyashankara Sharma ${ }^{1}$ \\ ${ }^{1}$ Department of Mechanical and Manufacturing Engineering, Manipal Institute of Technology, \\ Manipal Academy of Higher Education, Manipal, Karnataka - 576104, India
}

\begin{abstract}
The objective of this paper is to review the hygrothermal environment effects on Glass Fiber Reinforced Polymer (GFRP) composites. A brief summary of the hygrothermal phenomenon and its mechanisms of GFRP is followed by detailed review of hygrothermal effects on the GFRP. The review also includes the different hygrothermal aging tests viz., cold soaking, boiling soaking, thermal shocks and use of environmental chamber, procedures and significance. At the end, hygrothermal effects on the individual constituents of GFRP viz., fiber, matrix and the fiber-matrix interface, are discussed.
\end{abstract}

Keywords: Hygrothermal Aging, GFRP, Accelerated Aging

\section{Introduction}

In general, "composite" means "a material prepared by two or more different constituents" or "a combination of two or more different constituents, which are mixed at macroscopic level to get the best of their properties" [1,2].

Glass Fiber Reinforced Polymer (GFRP) composites have gained an extensive application in marine, aerospace, automobile and construction industries. Composite materials are not only used to produce new products, but also are used to repair and rehabilitate of existing parts [3]. GFRP composites are also widely used in architectural applications viz., roofing and partition walls [4]. The physical and mechanical properties of GFRP composites could be affected by humidity, elevated temperatures, water, alkalis and other harsh environments in service life $[5,6]$. The reliability and performance of composite materials over long time period is the concern to be addressed. There are several ways to investigate hygrothermal effects including some empirical methods for accelerated aging or real exposure tests. The purpose of this paper is to review the different tests available for hygrothermal aging conditions and summarize the procedure and significance of each test.

${ }^{*}$ Corresponding author: c.aakarshit21@gmail.com 


\subsection{Hygrothermal Diffusion}

Thermal and moisture gradients are the major contributors for hygrothermal diffusion. In most of the cases absorption of water or moisture obeys Fick's law. Diffusion is determined by the moisture concentration gradient between the surrounding environment and material, producing continuous absorption till saturation point reaches. The rate of diffusion rises swiftly with increase in temperature $[7,8]$.

\subsection{Theory of moisture absorption}

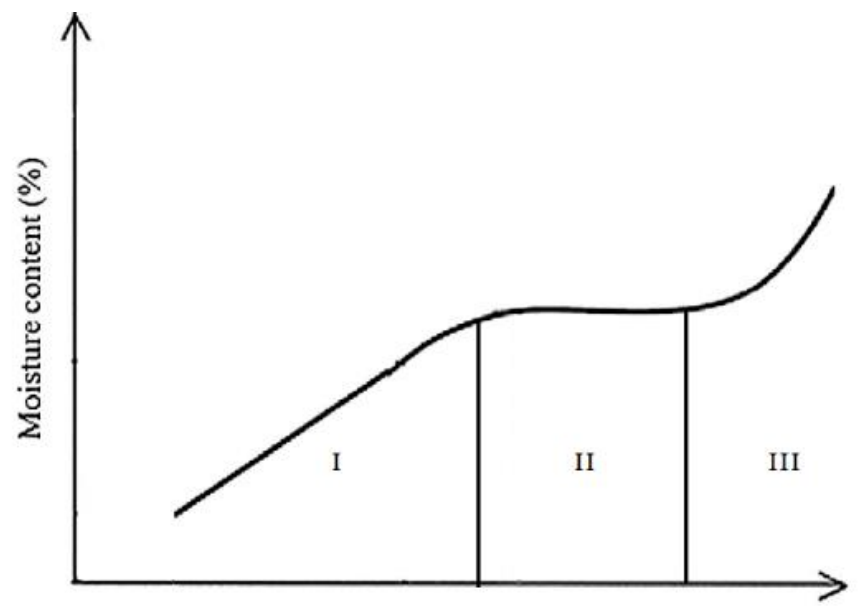

Square root of time (min)

Fig. 1. Moisture absorption curve

Fig. 1 shows three stages of moisture absorption [9],

I - Moisture absorption is Fickian, means, the curve follows linearity and observed in the rubbery state of polymers.

II - Once saturation point reaches, the curve deviate from linearity.

III - Moisture absorption is non-Fickian pattern, sudden rise in absorption due to microcracks or delamination or voids in the matrix or poor boding at fiber matrix interface.

\section{Literature Review}

S. Larbi et al. [10] investigated the effects of hygrothermal conditioning on mechanical properties of glass fiber reinforced polymer (GFRP) laminates. The laminates were kept in sea water at room temperatures for different time periods. The weight of the samples was noted down on regular intervals. During each weighing, samples were dried using an absorbent to remove water on the outer surfaces. The results show that the absorption kinetics is Fickian at the beginning of the process; but in the long term it is non-Fickian. This could be due to an irreversible degradation of material of lixiviation or hydrolysis 
type. Also, there was weight loss of samples in long term due to the harmful nature of the high $\mathrm{pH}$ of seawater that caused degradation of the matrix. Tests were conducted for composite properties after oven drying. Three-point bending characterization of materials aged hygrothermally had a negative impact. It was particularly illustrated with a loss of tensile strength.

B. C. Ray [11] worked on unidirectional and woven carbon fiber composite specimens at room temperature and at varied higher temperature to assess the environmentally induced damage in composites. At elevated temperature, faster is hygrothermal ageing, rises the moisture uptake rate. The interfacial bonding of fibers and matrix was more affected by aging at elevated temperature due to longer time of exposure. The effect of swelling and thermal stress is greater at elevated temperature. The non Fickian behavior could be correlated to the creation of supplementary free volume in the composite by viscoelastic effects or hydrolysis or by a combination of both. The hygrothermally created weaker and porous interface might lead to capillarity to absorb moisture molecules into the composites at elevated temperature.

S. Shivakumar and Shivarudraiah [12] studied hygrothermic behavior of GFRP, by exposing the composite specimen in water at 30,50 and $70^{\circ} \mathrm{C}$ for a period of 200 days. It was observed that the moisture uptake rate and moisture content were increased with increase in immersion time. The moisture uptake percentage of composites with respect to immersion time was far greater in the case of elevated temperature compared to the room temperature. The debonding between fiber and matrix at interface due to swelling, creates voids which act as a reservoir for moisture. Also, the results revealed that hygrothermal aging conditions for longer duration (200 days) and at higher temperature $\left(70^{\circ} \mathrm{C}\right)$ decreased the flexural strength by $30 \%$ as compared to virgin samples. But at the same time, thickness of the samples increased notably.

A. Rashdi et al. [13] investigated the effects of water absorption on the mechanical properties of kenaf fiber-polyester composites. Specimens were prepared with different weight percentages of fiber. The specimens were immersed for 4 months at $25^{\circ} \mathrm{C}$ in distilled water. Maximum specimens grasped the saturation point of moisture content in about 1920 -2400 hours. Increase in the percentage of weight of the fiber leads to an improvement of the tensile properties of the dry specimen, but a decline in the tensile properties of the immersed specimen due to the moisture absorption.

H. N. Dhakal et al. [14] worked on the water absorption effects on the mechanical properties of the hemp fiber-polyester resin composites. The specimens were soaked in deionized water at room and boiling temperatures for varied time intervals. The pattern for water absorption is found to follow Fickian behavior at room temperature, but it follows non-Fickian pattern at the boiling temperature. It was observed that, there is rise in weight of the samples $(23 \%)$ in boiling water compared to samples soaked in water at room temperature. The faster and higher weight gain of the samples aged in boiling water, leads to interfacial cracks because of degradation at the fiber matrix interface. The tensile strength of aged samples is higher than that for unaged samples. This might be due to high content of water that causes swelling in the fibers, which could have filled the gaps (voids) between the fiber and matrix and ultimately might have led to increase in the tensile properties of the composites.

H. S. Almeida et al. [15] investigated the effect of hygrothermal aging effects on tensile, compressive, in-plane and interlaminar shear properties of carbon fiber/epoxy laminates. The specimens were subjected to an accelerated hygrothermal aging at $80^{\circ} \mathrm{C}$ and $90 \%$ relative humidity for 60 days as per ASTM D5229M standard. It was observed that there was $0.42 \%$ of weight of specimens increase due to moisture absorption and reached saturation level in around 33 days. Tensile strength reduced by $15 \%$ for aged laminates. 
The SEM analysis indicated the degradation of the epoxy matrix, which led to fall in interfacial bonding, followed by decrease in tensile strength.

R. Zenasni and A. S. Bachir [16] investigated the effect of hygrothermo-mechanical aging on the inter-laminar fracture behavior of GFRP. Hygrothermo-mechanical aging characterization was carried out to know the loss in crack propagation resistance, on cantilever beam and notched flexural inter-laminar fracture tests.

Z. Sereir and N. Boualem [17] worked on the effects of long term hygrothermal loading on the hybrid composites. They also analyzed inter laminar stresses for the specimen by 3 point bending test, that resulted in change in the properties.

S. Pilli et al. [18] worked on the mechanical properties and long-term durability of composites under the influence of moisture. The test technique was developed to accelerate humidity by rising the pressure inside the test chamber for moisture ingression.

Y. I. Tsai et al. [19] worked on water absorption and mechanical property tests. The specimens were examined after immersion in water for 32 weeks at varied temperatures. Later specimens were weighed to calculate the moisture uptake percentage. The short beam strength was decreased while there was increase in moisture uptake, with temperature and immersion time.

R. M. Rowell et al. [20] studied the aspen fiber polyester resin with micro filler materials for cyclic humidity and water soaking conditions. Specimens have shown increase in moisture absorption. The addition of micro fillers decreases the moisture absorption compared to composites without any fillers.

\section{Hygrothermal Aging}

There are several ways to investigate hygrothermal effects including some empirical methods for accelerated aging or real exposure tests. Each has its own advantages and limitations. Real exposure tests consume lot of time to perform $[5,6,7]$.

Different hygrothermal aging tests are as follows;
1. Cold soaking
2. Boiling soaking
3. Thermal shocks
4. Use of environmental chamber

\subsection{Cold Soaking}

The composite specimens are soaked in water at room temperature (Fig. 2). During testing, specimens are removed from water weekly once, dried with paper napkin and weighed by an electrical balance with least count of $1 \mathrm{mg}$. The weight and time periods are noted down to analyze uptake moisture. Similarly, thickness of specimens are measured for any swelling. 


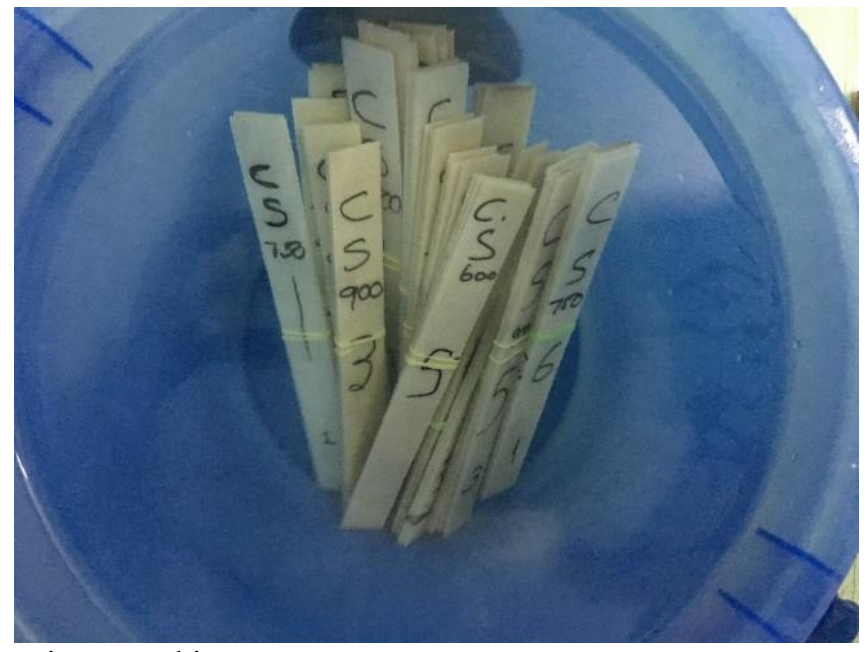

Fig. 2. Specimens immersed in water at room temperature

\section{Significance}

The water absorption is not typically in the form of liquid. It comprises of molecular group of hydrogen bonds linked to the polymer molecule chains. Adding to that, water could be absorbed by "capillary action" along the microcrack present in the specimens [11, 21, 22].

\subsection{Boiling Soaking}

The specimens are dried in an oven between 100 to $110{ }^{\circ} \mathrm{C}$ for a period of 12 hours. Later the specimens are weighed and measured for thickness. The specimens are boiled for 2 hours (Fig. 3) and instantly weight and thickness are measured. Specimens are re-dried in oven for 24 hours and again measured for weight and thickness. The process is repeated 10 times for a total of 20 hours of boiling [14].

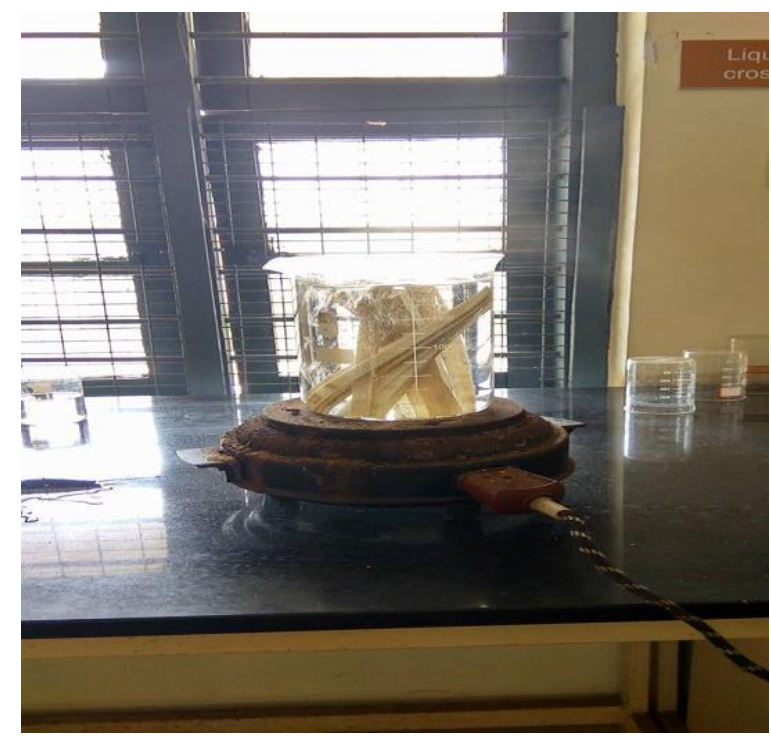

Fig. 3. Specimens in Boiling Environment 


\section{Significance}

Water absorption increases rapidly with rise in temperature. The water molecules migrate from higher concentration to the lower concertation region in the composite materials.

\subsection{Thermal Shocks}

In order to identify the effect of sudden changes in environment, specimens are placed in an oven maintained at $70{ }^{\circ} \mathrm{C}$ for a period of 2 hours (Fig. 4) and then immediately placed in freezing temperature of $-10{ }^{\circ} \mathrm{C}$ for another 2 hours. The process is repeated for 5 cycles.

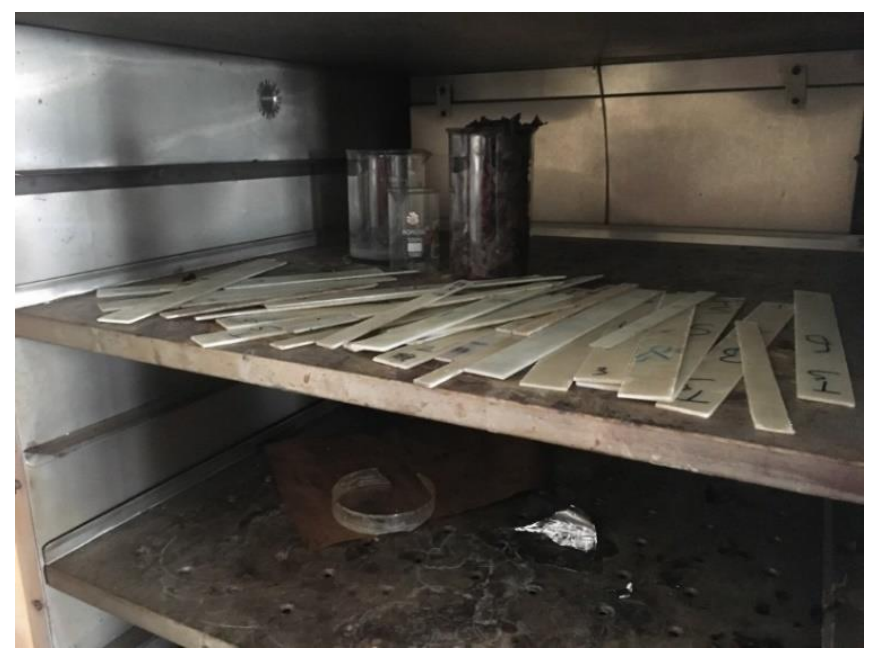

Fig. 4. Specimens in oven

\section{Significance}

Sudden change in temperature from hot to cold region or vice versa has impact in residual stresses, due to differences in thermal expansion coefficients of the constituents. Residual stresses could result in initiation and propagation of microcracks. Under continued thermal cycling microcracks endure to grow in number and size, which could result in degradation of stiffness and other matrix-dominated properties.

\subsection{Use of Environmental Chamber}

The specimens are kept in environmental chamber at known relative humidity (RH), temperature and time period. The specimens are withdrawn at consistent intervals, wiped dry to take away the surface moisture and then weighed using an electronic balance to monitor the mass change behaviour or moisture diffusion $[12,15]$.

For the study of the behaviour of the composite under high humidity and temperature conditions one should,

1. know the temperature and humidity ranges for which the composite is exposed to during its designed life.

2. know what properties of the composite are most important for the further technological performance of the material.

3. study the change of these properties by increasing wet mass of standard probes at a given temperature for different relative humidity $(\mathrm{RH})$.

4. repeat the study in step 3 for different temperatures. 
5. correlate the results of the studies proposed in steps 3 and 4 .

\section{Significance}

FRP composites exposed to humid environment with elevated temperature absorb moisture by instantaneous surface absorption and diffusion. An elevated temperature enacts like an activator for moisture diffusion throughout the composite.

\section{Hygrothermal Effects}

Hygrothermal effects on GFRP composites depend on the effects on the individual constituents viz., fiber, matrix and the fiber matrix interface. But the overall effects depend on the hygrothermal effects on the dominant component.

\subsection{Effects on Glass Fiber}

The effect of water on glass fibers could be established from the following chemical equations. A sequence of reactions lead to cleavage of silicon-oxygen bonds and to their conversion to hydroxysilane.

$$
\begin{aligned}
& \mathrm{Si}-\mathrm{ONa}+\mathrm{H}_{2} \mathrm{O} \longrightarrow \mathrm{Si}-\mathrm{OH}+\mathrm{NaOH} \\
& \mathrm{Si}-\mathrm{O}-\mathrm{Si}+\mathrm{OH}^{-} \longrightarrow \mathrm{Si}-\mathrm{OH}+\mathrm{Si}-\mathrm{O}^{-} \\
& \mathrm{Si}-\mathrm{O}^{-}+\mathrm{H}_{2} \mathrm{O} \longrightarrow \mathrm{Si}-\mathrm{OH}+\mathrm{OH}^{-}
\end{aligned}
$$

The overall chemical reaction could result in degradation and micro flaw formation on the glass fiber surface, due to the rise in the $\mathrm{pH}$ level, since the glass fibers are covered and protected by the matrix material. But, microcracks or voids present in composite materials might allow water to diffuse through the matrix. The matrix and fiber matrix interface degrade at a higher rate compared to glass fiber.

\subsection{Effects on Polymer Matrix}

Moisture absorption into a polymer matrix affects both physical and mechanical properties through different mechanisms viz., swelling, hydrolysis, crazing and plasticization. Hygrothermal environments have robust effects on the polymer properties. These effects could be named as reversible and irreversible. For example, at the point when water diffuses into the polymer matrix, it plasticizes and swells the polymer molecular network, diminishes the surface free energy and enhance the free volume of the polymer, consequently actuating a decrease in the glass transition temperature (Tg). This process is of reversible effects, so the property will recuperate after drying the polymer material.

The higher exposure span to moisture results in irreversible damage (hydrolysis and microcracking). Hydrolysis might be the prime reason for the polymer weight loss after long term soaking. On the other hand, microcracking in the matrix might contribute to decrease in mechanical properties.

\subsection{Effects on the Fiber / Matrix Interface}

The interface is regarded as the non-homogenous region that lies between the matrix and the fibers. Usually matrix is bulk material, which absorbs more moisture compared to the fibers. The mismatch in the moisture absorption leads to localized stress and strain field because of nonuniform volumetric expansion between the fibers and matrix. The localized 
stress and strain field between fibers and matrix will lead to initiation and propagation of crack throughout the boundary layer of the fiber matrix interface.

\section{Concluding Remarks}

The hygrothermal environment effects on Glass Fiber Reinforced Polymer (GFRP) composites was reviewed in this paper. The fundamental points can be summarised as follows:

1. Moisture absorption into a polymer matrix affects both physical and mechanical properties through different mechanisms viz., swelling, hydrolysis, crazing and plasticization. Hygrothermal environments have robust effects on the polymer properties.

2. Thermal and moisture gradients are the major contributors for hygrothermal diffusion. In most of the cases absorption of water or moisture obeys Fick's law. The results show that the absorption kinetics is Fickian for shorter duration; but in the long term it is non-Fickian.

3. Also, the results revealed that hygrothermal aging conditions for longer duration and at higher temperature had negative impact on physical and mechanical properties of GFRP composites.

\section{References}

1. K. K. Chawla, Composite Materials Science and Engineering (Springer Science \& Business Media, New York, 2012)

2. R. M. Jones, Mechanics of Composite Materials (CRC Press, Taylor \& Francis Group, Philadelphia 1998)

3. F. C. Campbell, Manufacturing Processes for Advanced Composites (Elsevier, London, 2003)

4. A. K. Kaw, Mechanics of Composite Materials (CRC press, Taylor \& Francis Group, Philadelphia 2005)

5. L. H. Hihara, R. P. Adler, R. M. Latanision, Environmental Degradation of Advanced and Traditional Engineering Materials (CRC Press, 2013)

6. R. Martin, Aging of Composites (CRC Press, Washington 2008)

7. V. K. Thakur, Green composites from natural resources (CRC Press, Washington 2013)

8. Y. Zhong, S. C. Joshi, Mat. Des. 92, 866 (2016)

9. K. E. Pickering, Properties and performance of natural-fibre composites (CRC Press, Washington 2008)

10. S. Larbi, S. Bensaada, A. Bilek, S. Djebali, AIP Conference Proceedings, 1653 (2015)

11. B. C. Ray, J. of Col. Int. Sci. 298, 111 (2006)

12. S. Shivakumar, Shivarudraiah, I. J. Adv. Eng. Tech. 1, 225 (2010)

13. A. Rashdi, M. S. Salit, K. Abadan, M. M. H. Megat, Pert. J. Sci. Tech. 18, 433 (2010)

14. H. N. Dhakal, Z. Y. Zhang, M. O. W. Richardson, Comp. Sci. Tech. 67, 1674 (2007)

15. J. H. S. Almeida, S. D. Souza, E. C. Botelho, S. C. Amico, J. Mat. Sci. 51, 4697 (2016)

16. R. Znasni, A. S. Bachir, J. Ther. Comp. Mat. 19, 385 (2006)

17. Z. Sereir, N. Boualem, J. Theo. App. Fra. Mech. 47, 145 (2007) 
18. S. Pilli, P. Simmons, L. Kevin, J. Comp. Part A, 40, 1501 (2009)

19. Y. I. Tsai, E. J. Bosze, E. Barjastech, T. S. R. Nut, J. Comp. Sci. Tech. 69, 432 (2009)

20. R. M. Rowell, S. E. Lange, R. E. Jacobson, Proceedings of the $7^{\text {th }}$ Pacific Rim Biobased Composites Symposium (2004)

21. E. Osman, M. W. Rashid, M. E. A. Manaf, E. Mohamad, M.R. Salleh, T. Ito, T. Moriga T. J. Adv. Man. Tech. (2016)

22. E. C. Botelho, L.C Pardini, M. C. Rezende, J.Mat. Sci. 41, 7111 (2006) 